\title{
Power System Security with Contingency Technique by Using SSSC \& UPFC
}

\author{
Chandrashekhar S. Hiwarkar, P. G. Burade
}

\begin{abstract}
Now days' electrical power requirement has enlarged expanding as expansion \& restructuring of electrical power system (PS) for generation \& transmission in power sector is critically limited due to current resources \& environmental circumstances.

As outcome, approximately of corridors of power transmission overhead lines are greatly loaded \& congested. Also major issue of power system voltage stability becomes power transfer restricted and capability issue. A Modern power electronics technology FATCS considered device Static Synchronous Series Compensator (SSSC) is VSC demanded series FACTS equipment. Unified power flow controller (UPFC) is to manage power flow $(P F)$, voltage magnitude \& phase angle. In this research paper suggested to maintain voltage magnitude as well as PF of faulty lines. The consequence of mutation of PS parameters like voltage, phase angle, active power, reactive power, \& overall power factor with \& without SSSC \& UPFC have also incorporated. Assessment of PS safety is essential in society to expand customs to sustain system functions when one or more components fail. A $P S$ is "secure" when it can defy loss of one or more ingredients \& still go on working without major problems. The Contingency event investigation technique is taken to identify electrical node $P F$ in faulty transmission lines (TL). The Performance of PS has been tested on IEEE 14-Bus System.
\end{abstract} flow.

Index Terms: SSSC, UPFC, Contingency technique, Power

\section{INTRODUCTION}

The desired amount of prohibited node PF via TL is interpreted into essential injected voltage. The dominance of direct current (D.C) bus voltage plays important role in electrical PF into overhead TL (OTL). PF manages attained via reactive section of voltage injected. It is noted that SSSC acts as capacitor when system PF via OTL is enlarged \& as an inductor while PF is diminished. The system described in Figure 1 consists fundamental configuration of SSSC. For taking concern of $\mathrm{PF}$ in transmission line \& voltage magnitude at buses use SSSC \& UPFC as a FACTS device rated \pm 70 MVAR \& \pm 150 MVAR respectively. Further, transformer has capacity of 300MVA. The main advantage in execution of VSC considered SSSC \& VSI based UPFC are adequately maximum value of storage capacitance \& consequently not cost effectual. [1]

Revised Version Manuscript Received on September 16, 2019.

C. S. Hiwarkar currently working as Assistant Professor in Electrical Engineering Department at KDK College of Engineering, Nagpur, INDIA

Dr. Prakash G. Burade presently working as professor,head of Electrical Department \& Dean Academics at SITRC,Nashik, India.

\section{WORKING PRINCIPAL OF FACTS DEVICES}

\section{A. Static Synchronous Series Compensator (SSSC)}

SSSC is series compensation device that is connected controller based on VSC which is shown in fig 1. SSSC is operated moreover capacitive or inductive injected voltage compensation. If line current via 90 lead in AC series injected voltage in SSSC, capacitive series voltage compensation is attain in TL.

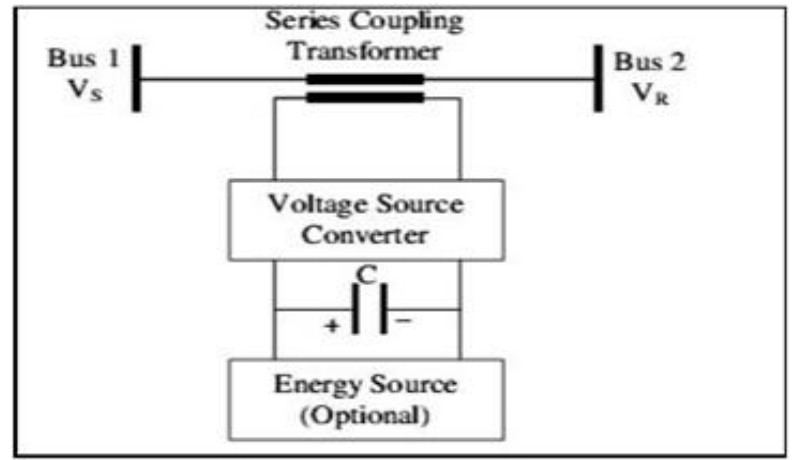

Fig.1: Schematic illustration of SSSC.

On opposite, if AC line injected series voltage of SSSC guide line current via $90^{\circ}$, inductive series compensation may implement. The injection of voltage into line ought to take place only while power is to be subtracted from or added into line. It is too distinguished SSSC acts as capacitor while system $P F$ via line is amplified $\&$ as an inductor when $P F$ is to be reduced. [1]

\section{B. Unified Power Flow Controller (UPFC)}

UPFC is made up of 2 voltage source converters; series \& shunt converter SSSC \& STATCOM respectively, coupled via normal DC voltage link. The energy preserving capacity of DC capacitor is usually low \& then shunt converter inject APF from transmission grid in accurately similar quantity as active power being injected via series converter.

If this is not subsequently, DC-link voltage ought amplify or reduce with admiration to rated voltage, formation on net power taken up or returned via mutual converters. Under different conditions, RPF in shunt or series converter may manage separately, yielding vast flexibility to PF control.

The coupling transformer is utilized to plug in equipment to arrangement. Figure 2 presents schematic diagram of 3 phases UPFC connected to TL. PF Control can be attained via adding vector of series voltage, Vs with certain amplitude, $\left|V_{s}\right| \&$ phase shift (PS), $\delta$ to $\mathrm{V}_{1}$. 
This introduces fresh line voltage $V_{2}$ with another magnitude $\&$ PS. As the angle $\delta$ varies, phase shift $\delta$ among $\mathrm{V}_{1} \& \mathrm{~V}_{2}$ also varies. Figure 2 presents schematic diagram of UPFC \& characteristics of voltage \& current [6].

With existence of 2 converters, UPFC not only can provide reactive power but also active power.

In this operation, series converter swaps mutually real \& reactive power with TL. The equation for active $\&$ reactive power is given as below:-

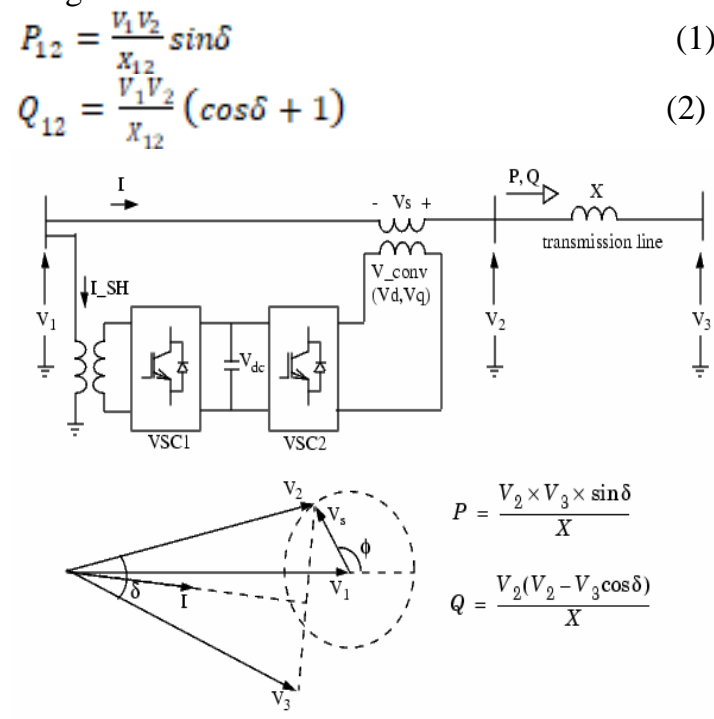

Figure 2: Schematic diagram of UPFC

\section{IEEE 14-Bus (Test System)}

The single line figure of IEEE 14-bus standard test system is presented in figure 3 that is made up of 20 TL. 5 no. synchronous machines, consisting 2 generators, located at buses $1 \& 2$ as well as 3 synchronous compensators utilized for RPF handles, located at buses 3, $6 \& 8$.

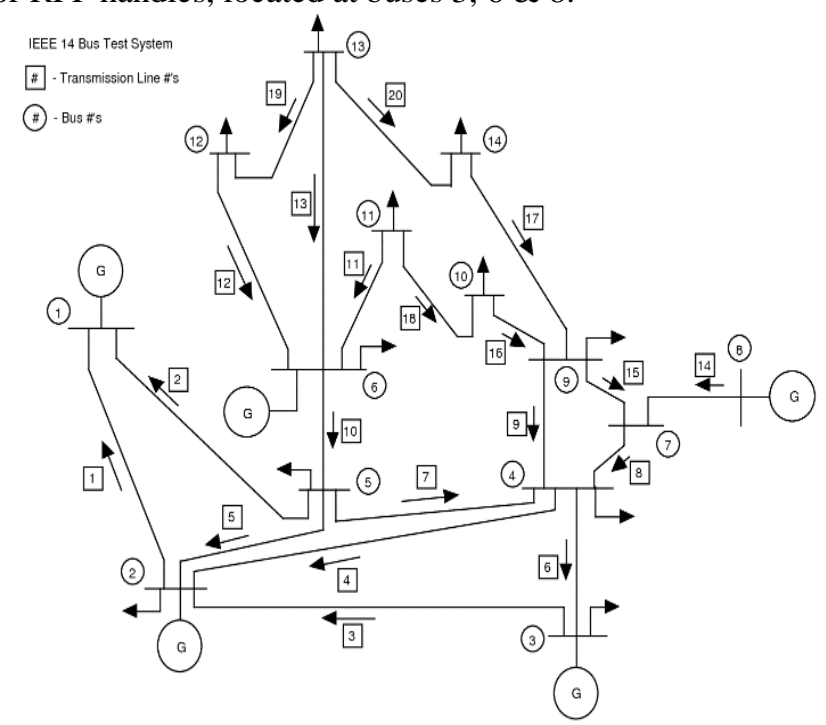

Figure 3: Single line diagram of IEEE 14 Bus

\section{CONTINGENCY SELECTION}

Maintaining PS security is one of most demanding practical tasks for PS engineers. The safety determination is necessary job as it provides knowledge about system while it is in state of contingency.

Contingency analysis function is used to decide consequence of faults such as failures of devices, TL error etc. \& to apply for obligatory actions to prevent PS instability $\&$ dependable. The off line analysis of individual contingency is tedious job because PS have a huge amount of elements.

Actually, only selected contingencies will guide to severe conditions in PS. Recognize severe contingencies is referred as contingency selection \& this can be performed via manipulative presentation indices for each line. The contingency investigation technique is much time overwhelming and its convoluted calculation of complex AC load flow computation subsequent to every probable fault at different generators \& TL [7].

In sort to alleviate above issue, an automatic contingency screening (CS) demand is assume that recognize \& ranks faults that actually due to abnormal circumstances. So CS \& ranking for unsymmetrical fault. The contingencies are screened as per to severity index or PI in which maximum value of these indices ssymbolize maximum level of hardness.

The major purpose of this work is to hold contingency selection via manipulative the 2 types of performance indices namely, active power performance index (PIP) \& reactive power performance index (PIQ) for individual line fault. (PIQ) have been calculated for IEEE-14 bus test system that is presented in fig 3 .

Employing algorithm implemented in MATLAB software. With help of Fast Decoupled Load Flow (FDLF), PIP \& PIQ played out in MATLAB \& contingency ranking is based. Founded on values of the PIQ, contingencies is ranked in TL contingency guiding to maximum value of PIQ has been ranked $1 \&$ at least values of PIQ is ranked last. The solutions of active PF (APF), reactive PF (RPF) in different TL \& bus voltages at the buses has been studied [9]. Since contingency analysis techniques involve prediction of effect of individual contingency cases, the above process becomes very tedious \& time consuming while complex PS network is wide and big.

In sort to avoid exceeding problem of CS or contingency selection technique found critical concern. As it found overall probable faults do not cause overload voltage or beneath voltage in different PS devices. The procedure of recognizing contingencies that really go to encroachment of real operational restrictions is termed as contingency selection.

The contingencies are chosen via manipulative type of severity indices termed as Performance Indices (PI). These indices are computed utilizing conventional power load flow algorithms for single contingencies in an off line mode. Set along values attained contingencies are ranked in manner, where they obtained maximum value of PI is ranked $1^{\text {st }}$.

The investigation is basically preliminary via eventuality that is ranked $1 \&$ is persisted in from no severe contingencies are available. Here 2 kinds of PI, that is highly utilize, these are active power, performance index (PIP) \& reactive power performance index (PIQ). PIP shows violation of line APF \& is shown via equation (3).

$$
P I p=\sum_{i=0}^{\mathbb{1}}\left(\frac{p_{i}^{i}}{p_{\max }}\right)
$$


Where,

$\mathrm{Pi}=\mathrm{APF}$ in line $\mathrm{i}$,

Pimax =Maximum APF in line $i$,

$\mathrm{N}$ is precise element,

$\mathrm{L}$ is overall no of TL in system If $\mathrm{n}$ is big figure, PI will be low bit if overall PFs are in restrictions \& larger if 1 or further TL are overloaded, value of $\mathrm{n}$ is kept unity.

The highest PF in every line is considered utilizing formula,

$$
\operatorname{Pimax}=\frac{V_{i} V_{j}}{x}
$$

Here,

$\mathrm{Vi}=$ Voltage at bus $\mathrm{i}$

$\mathrm{Vj}=$ Voltage at bus $\mathrm{j}$

$\mathrm{X}=$ Reactance of line linking bus $\mathrm{i} \&$ bus $\mathrm{j}$

Another PI parameter that is utilized to bus voltage magnitude violations.

It mathematically presented in eq. 3,

$$
P I \nu=\sum_{i=1}^{N p q}\left\{\frac{2 \text { Vi-Vinom } j}{\text { Vimax-Vimin }\}}\right\}
$$

Where $\mathrm{Vi}=$ voltage of bus i, Vimax \& Vimin are highest $\&$ lowest voltage limits, Vinom is average of Vimax \& Vimin, $\mathrm{Npq}$ is overall no. of load buses in system [12].

\section{CONTINGENCY RANKING OF IEEE-14 BUS SYSTEM}

To search Contingency Ranking subsequently technique is assumed: The AC power load flow program for contingency analysis (CA) by adopting the Fast Decoupled Load Flow (FDLF) algorithms that provides a quick solution for the contingency investigation as it possesses benefits of matrix alteration equation included \& applied to suggest issue of possible contingencies concerning TL fault without reinventing system Jacobian matrix for alliteration. The ranking of line contingency is shown in shown table1.

\begin{tabular}{|c|c|c|c|}
\hline Fault Line No. & PIP & PIQ & Ranking \\
\hline 1 & 1.1693 & 7.3032 & 10 \\
\hline 2 & 0.9807 & 7.6696 & 11 \\
\hline 3 & 1.1654 & 10.0014 & 7 \\
\hline 4 & 0.9999 & 7.3213 & 12 \\
\hline 5 & 0.9820 & 8.8759 & 9 \\
\hline 6 & 0.9640 & 13.2572 & 2 \\
\hline 7 & 0.9915 & 0.3566 & 19 \\
\hline 8 & 1.0747 & 1.1753 & 17 \\
\hline 9 & 0.9807 & 10.5776 & 4 \\
\hline 10 & 1.2396 & 1.6047 & 16 \\
\hline 11 & 1.0142 & 9.5907 & 8 \\
\hline 12 & 1.0127 & 1.8089 & 15 \\
\hline 13 & 1.0569 & 1.3669 & 18 \\
\hline 14 & 1.0072 & 10.4518 & 6 \\
\hline 15 & 1.0759 & 0.0844 & 20 \\
\hline 16 & 1.0114 & 13.3464 & 1 \\
\hline 17 & 1.0164 & 2.3482 & 13 \\
\hline 18 & 1.0030 & 10.5217 & 5 \\
\hline 19 & 1.0008 & 12.5538 & 3 \\
\hline 20 & 1.0076 & 2.2891 & 14 \\
\hline
\end{tabular}

Table 1: Line by Line Contingency Ranking

\section{RESULTS AND DISCUSSION}

The system has total 20 no. TL, therefore we estimate for 20 line contingency circumstances via having fault on one line at time. The PI are summed in beyond table in which it can infer that fault in line no. 16 is mainly severe one \& fallout will effect heavy collision on overall system. The maximum value of PIQ for fault suggests that maximum attention be yielded for this communication channel while surgical procedure. The contingency has been set via ranking in which main severe contingency is ranked $1 \&$ list is ranked 20 that is presented in table 1 . Then here it analyzes one by one line from contingency ranking \& endpoints shown in table No. 2, 3, 4, and 5 with SSSC and UPFC.

The variations in electric potential, APF \& RPF with SSSC are presented in figure $4,5 \& 6$ and with UPFC are presented in figure $7,8, \& 9$ correspondingly.

Table 2: Voltage variations (VV) at Line No. 16 with SSSC

\begin{tabular}{|l|l|l|l|}
\hline Bus No. & Bus Voltage (BV) (Main) & BV (After Fault) & BV with SSSC \\
\hline 1. & 1.06 & 1.06 & 1.06 \\
\hline 2. & 1.045 & 1.045 & 1.045 \\
\hline 3. & 1.01 & 0.8701102 & 1.021002 \\
\hline 4. & 1.00737206 & 0.976645107 & 1.0210003 \\
\hline 5. & 1.00978292 & 0.999273311 & 1.008 \\
\hline 6. & 1.07 & 1.07 & 1.07 \\
\hline 7. & 1.05120246 & 1.045275968 & 1.052 \\
\hline 8. & 1.09 & 1.09 & 1.09 \\
\hline 9. & $\mathbf{1 . 0 4 0 2 0 6 8 6}$ & $\mathbf{0 . 8 3 1 8 9 2 8 7 1}$ & $\mathbf{1 . 0 5 0 1}$ \\
\hline 10. & $\mathbf{1 . 0 3 5 4 3 2 7 0}$ & $\mathbf{0 . 8 2 7 5 3 0 9 6 1}$ & $\mathbf{1 . 0 4 5}$ \\
\hline
\end{tabular}


Power System Security with Contingency Technique by Using SSSC \& UPFC

\begin{tabular}{|l|l|l|l|}
\hline 11. & 1.04780211 & 1.043258176 & 1.051201 \\
\hline 12. & 1.04926356 & 1.046920381 & 1.0521002 \\
\hline 13. & 1.04198704 & 1.038429205 & 1.05 \\
\hline 14. & 1.01653643 & 1.007809397 & 1.026 \\
\hline
\end{tabular}

Table 3: PF variations at Line No. 16 with SSSC

\begin{tabular}{|l|l|l|l|l|l|}
\hline Line No. & APF with Fault & RPF with Fault & Line No. & APF with SSSC & RPF with SSSC \\
\hline 1 & 219.07528 & 18.843217 & 1 & 220.285 & 18.4607 \\
\hline 2 & 103.65932 & 4.4666054 & 2 & 113.969 & 4.37595 \\
\hline 3 & 101.28245 & 0.6079161 & 3 & 111.356 & 0.59557 \\
\hline 4 & 76.416181 & 0.8169245 & 4 & 84.0166 & 0.80034 \\
\hline 5 & 56.671777 & 2.4210430 & 5 & 62.3084 & 2.37190 \\
\hline 6 & 30.215410 & 9.1470338 & 6 & 33.2206 & 8.96139 \\
\hline 7 & 80.703680 & 11.870645 & 7 & 88.7306 & 11.6297 \\
\hline 8 & 37.180518 & 4.3931969 & 8 & 40.8785 & 4.30403 \\
\hline 9 & 21.162005 & 0.8574258 & 9 & 23.2668 & 0.84002 \\
\hline 10 & 60.773799 & 4.1488491 & 10 & 66.8184 & 4.06464 \\
\hline 11 & 10.561110 & 4.3661960 & 11 & 11.6115 & 4.27758 \\
\hline 12 & 10.719247 & 2.1202118 & 12 & 11.7854 & 2.07718 \\
\hline 13 & 24.437191 & 6.3732922 & 13 & 26.8677 & 6.24394 \\
\hline 14 & 88.005863 & 12.944723 & 14 & 96.7590 & 12.6820 \\
\hline 15 & 37.180518 & 6.8176647 & 15 & 40.8785 & 6.6793 \\
\hline 16 & 6.4686256 & 1.4869327 & 16 & 10.1120 & 1.45675 \\
\hline 17 & 12.916960 & 2.2092927 & 17 & 13.9832 & 1.97460 \\
\hline 18 & 6.3462411 & 3.3971191 & 18 & 6.90782 & 2.98403 \\
\hline 19 & 2.3654228 & 0.7701694 & 19 & 2.60069 & 0.75453 \\
\hline 20 & 8.1714358 & 2.3726499 & 20 & 8.98418 & 2.324497 \\
\hline
\end{tabular}

Table 4: VV at Line No. 16 with UPFC

\begin{tabular}{|l|l|l|l|}
\hline $\begin{array}{l}\text { Bus } \\
\text { No. }\end{array}$ & $\begin{array}{l}\text { BV } \\
\text { (Main) }\end{array}$ & BV (After Fault) & BV with SSSC \\
\hline 1. & 1.06 & 1.06 & 1.06 \\
\hline 2. & 1.045 & 1.045 & 1.045 \\
\hline 3. & 1.01 & 0.8701102 & 1.021002 \\
\hline 4. & 1.00737206 & 0.976645107 & 1.0210003 \\
\hline 5. & 1.00978292 & 0.999273311 & 1.008 \\
\hline 6. & 1.07 & 1.07 & 1.07 \\
\hline 7. & 1.05120246 & 1.045275968 & 1.052 \\
\hline 8. & 1.09 & 1.09 & 1.09 \\
\hline 9. & $\mathbf{1 . 0 4 0 2 0 6 8 6}$ & $\mathbf{0 . 8 3 1 8 9 2 8 7 1}$ & $\mathbf{1 . 0 6 0 1}$ \\
\hline 10. & $\mathbf{1 . 0 3 5 4 3 2 7 0}$ & $\mathbf{0 . 8 2 7 5 3 0 9 6 1}$ & $\mathbf{1 . 0 5 5}$ \\
\hline 11. & 1.04780211 & 1.043258176 & 1.051201 \\
\hline 12. & 1.04926356 & 1.046920381 & 1.0521002 \\
\hline 13. & 1.04198704 & 1.038429205 & 1.05 \\
\hline 14. & 1.01653643 & 1.007809397 & 1.026 \\
\hline
\end{tabular}

TABLE 5: PF variations at Line No. 16 with SSSC

\begin{tabular}{|l|l|l|l|l|l|}
\hline $\begin{array}{l}\text { Line } \\
\text { No. }\end{array}$ & APF with Fault & RPF with Fault & Line No. & APF with UPFC & RPF with UPFC \\
\hline 1 & 219.052 & 18.843 & 1 & 220.2 & 18.46079 \\
\hline 2 & 103.659 & 4.46660 & 2 & 113.9 & 4.375956 \\
\hline 3 & 101.282 & 0.60791 & 3 & 111.3 & 0.595578 \\
\hline
\end{tabular}


International Journal of Recent Technology and Engineering (IJRTE) ISSN: 2277-3878, Volume-8, Issue-2S11, September 2019

\begin{tabular}{|l|l|l|l|l|l|}
\hline 4 & 76.4161 & 0.81692 & 4 & 84.01 & 0.800345 \\
\hline 5 & 56.6717 & 2.42104 & 5 & 62.30 & 2.371908 \\
\hline 6 & 30.2154 & 9.14703 & 6 & 33.22 & 8.961395 \\
\hline 7 & 80.7036 & 11.8706 & 7 & 88.73 & 11.62973 \\
\hline 8 & 37.1805 & 4.39319 & 8 & 40.87 & 4.304037 \\
\hline 9 & 21.1620 & 0.85742 & 9 & 23.26 & 0.840024 \\
\hline 10 & 60.7737 & 4.14884 & 10 & 66.81 & 4.064648 \\
\hline 11 & 10.5611 & 4.36619 & 11 & 11.61 & 4.277584 \\
\hline 12 & 10.7192 & 2.12021 & 12 & 11.78 & 2.077182 \\
\hline 13 & 24.4371 & 6.3732 & 13 & 26.86 & 6.243946 \\
\hline 14 & 88.0058 & 12.9447 & 14 & 96.75 & 12.68201 \\
\hline 15 & 37.1805 & 6.81766 & 15 & 40.87 & 6.6793 \\
\hline 16 & 6.46862 & 1.48693 & 16 & 11.11 & 1.356755 \\
\hline 17 & 12.9169 & 2.20929 & 17 & 13.98 & 1.974603 \\
\hline 18 & 6.3462 & 3.39711 & 18 & 6.907 & 2.9840352 \\
\hline 19 & 2.36542 & 0.77016 & 19 & 2.600 & 0.754539 \\
\hline 20 & 8.17143 & 2.37264 & 20 & 8.984 & 2.324497 \\
\hline
\end{tabular}

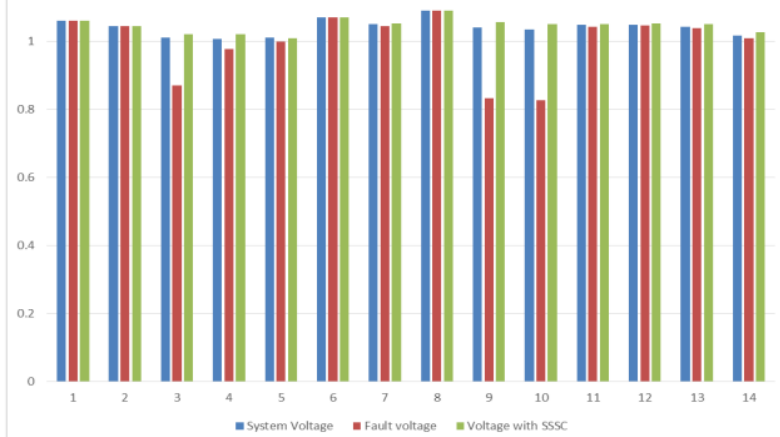

Fig.4. VV at Line no.16 with SSSC

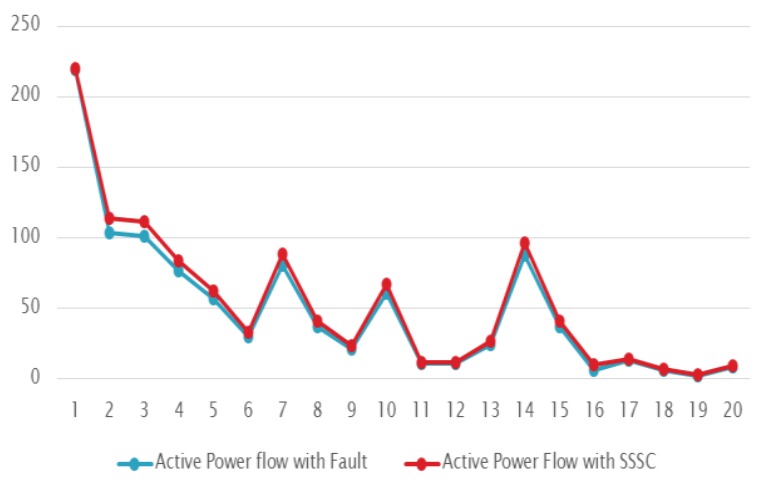

Figure 5. APF at Line no.16 with SSSC

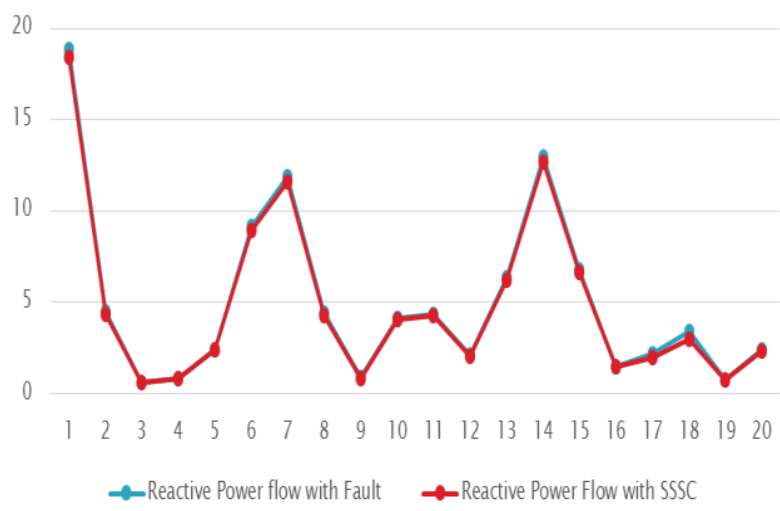

Figure 6. RPF at Line no.16 with SSSC

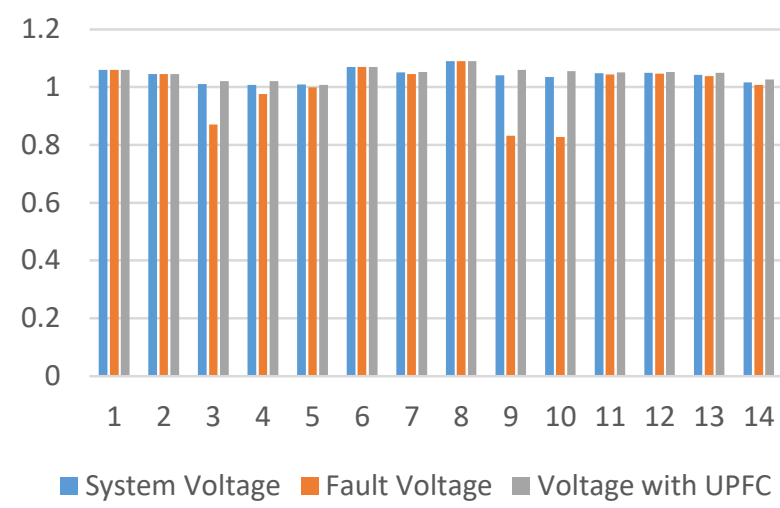

Figure 7. VV at Line no.16 with UPFC

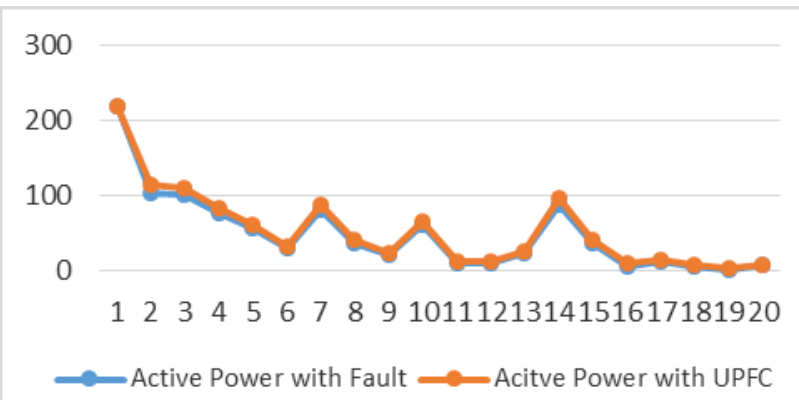

Figure 8. APF at Line no.16 with UPFC

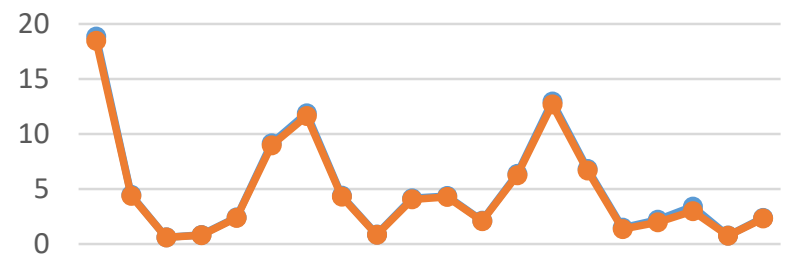

12234456778991011121314151617181920 - Reactive Power with Fault
- Reactive Power with UPFC

Fig.9. RPF at Line no.16 with UPFC.

Published By:

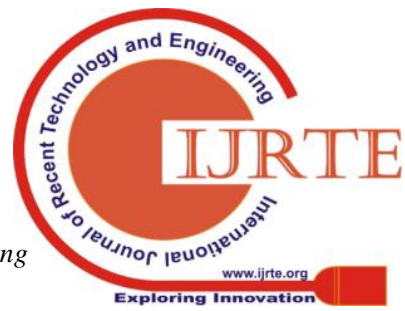




\section{CONCLUSION}

From outcomes we examine that, bus voltages beneath fault circumstances are drops down as well as $\mathrm{PF}$ is disturbing. After connecting SSSC to fault line, power flow is enhanced, but connecting UPFC to fault line, the power flow is improved better than SSSC.

Here we are comparing voltage variation, APF \& RPF with and without SSSC and UPFC of line no 16 that is important severe as per contingency investigation as well as $\mathrm{VV}$ of Bus no. $9 \& 10$ that are linked to line no. 16 in table 6 .

\section{Table 6: Comparison}

\begin{tabular}{|c|c|c|c|c|c|c|c|c|c|}
\hline \multirow{2}{*}{$\begin{array}{l}\text { Line } \\
\text { No./ } \\
\text { Bus } \\
\text { No. }\end{array}$} & \multicolumn{3}{|c|}{ Fault Condition } & \multicolumn{3}{|c|}{ With SSSC } & \multicolumn{3}{|c|}{ With UPFC } \\
\hline & $\begin{array}{l}\mathrm{V} \\
\mathrm{pu}\end{array}$ & $\begin{array}{l}\mathrm{P} \\
\mathrm{M} \\
\mathrm{W}\end{array}$ & $\begin{array}{l}\text { Q } \\
\text { MV } \\
\text { AR }\end{array}$ & $\begin{array}{l}\mathrm{V} \\
\mathrm{pu}\end{array}$ & $\begin{array}{l}\mathrm{P} \\
\mathrm{M} \\
\mathrm{W}\end{array}$ & $\begin{array}{l}\text { Q } \\
\text { MV } \\
\text { AR }\end{array}$ & $\begin{array}{l}\mathrm{V} \\
\mathrm{pu}\end{array}$ & $\begin{array}{l}\mathrm{P} \\
\mathrm{M} \\
\mathrm{W} \\
\end{array}$ & $\begin{array}{l}\text { Q } \\
\text { MV } \\
\text { AR }\end{array}$ \\
\hline $\begin{array}{l}\text { Line } \\
\text { No. } \\
16\end{array}$ & --- & $\begin{array}{l}6.4 \\
68 \\
\end{array}$ & $\begin{array}{l}1.48 \\
69\end{array}$ & --- & $\begin{array}{l}8.8 \\
12\end{array}$ & $\begin{array}{l}1.45 \\
67\end{array}$ & --- & $\begin{array}{l}11 . \\
112\end{array}$ & $\begin{array}{l}1.35 \\
6\end{array}$ \\
\hline $\begin{array}{l}\text { Bus } \\
\text { No. } \\
9 \\
\text { Bus } \\
\text { No. } \\
10\end{array}$ & $\begin{array}{l}0 . \\
83 \\
0 . \\
82\end{array}$ & --- & & $\begin{array}{l}1 . \\
05 \\
1 . \\
04\end{array}$ & ---- & & $\begin{array}{l}1.0 \\
16 \\
1.0 \\
51\end{array}$ & ---- & \\
\hline
\end{tabular}

\section{REFERENCES}

1. Akhilesh A. Nimje*, Chinmoy Kumar Panigrahi and Ajaya Kumar Mohanty, "Enhanced power transfer capability by using SSSC", Journal of Mechanical Engineering Research Vol. 3 (2), pp. 48-56, February 2011 ISSN $2141-2383$.

2. A. Seifi, S.Gholami, and A. Shabanpour, "Power Flow Study and Comparison of FACTS: Series (SSSC), Shunt (STATCOM), and Shunt-Series (UPFC)", the Pacific Journal of Science and Technology Volume 11. Number 1. (May 2010.)

3. Ji-Ho Park and Y.S. Baek, "Coordination Control of Voltage between STATCOM and Reactive Power Compensation Devices in Steady-State" Journal of Electrical Engineering \& Technology Vol. 7, No. 5, pp. 689 697, (2012.)

4. A. Berizzi, M. Delfanti, P. Marannino, M. Savino, and A. Silvestri, "Enhanced Security-Constrained OPF with FACTS Devices" IEEE Transactions on Power Systems, Vol. 20, No. 3 , (August 2005.)

5. J. Zhu, K. Cheung, Senior Member, D. Hwang, and A. Sadjadpour, "Operation Strategy for Improving Voltage Profile and Reducing System Loss" Transactions On Power Systems, Vol. 25, No. 1, (February 2010.)

6. Nashiren.F. Mailah, Senan M. Bashi, "Single Phase Unified Power Flow Controller (UPFC): Simulation and Construction", European Journal of Scientific Research ISSN 1450-216X Vol.30 No.4 (2009), pp.677-684

7. T. Güler, G. Gross, E. Litvinov, and R. Coutu, "On the Economics of Power System Security in Multi-Settlement Electricity Markets", IEEE Transactions on Power Systems, Vol. 26, No. 4, (November 2011.)

8. R. S. Wibowo, N. Yorino, M. Eghbal, Y. Zoka, and Y. Sasaki, "FACTS Devices Allocation With Control Coordination Considering Congestion Relief and Voltage Stability" IEEE Transactions On Power Systems, Vol. 28, No. 2, (May 2013.)

9. T. Mandloi, A. K. Jain "A study of power system security and contingency analysis" International Journal of Scientific Research Engineering \& Technology (IJSRET), ISSN 2278 0882 Volume 3, Issue 4, (July 2014.)

10. S. Ravindra, V. C. Veera Reddy, S. Sivanagaraju, "Power System Security Analysis under Generator Outage Condition" International Journal of Advanced Research in Electrical, Electronics and Instrumentation Engineering, Vol. 4, Issue 1, (January 2015.)

11. Dr. P. G. Burade, Dr. J. B. Helonde, "Optimal Location of FACTS devices on Enhancing system security," IJSER, vol.2, issue 4, pp.1-9, (April 2012.)

12. V. P. Doshi, S.A. Salgar, "Latest Trends In Contingency Analysis of Power System" Novateur Publications International Journal of Innovations in Engineering Research and
Technology [IJIERT] ISSN: 2394-3696 VOLUME 2, ISSUE 2, (FEB.-2015.)G. O. Young, "Synthetic structure of industrial plastics (Book style with paper title and editor)," in Plastics, 2nd ed. vol. 3, J. Peters, Ed. New York: McGraw-Hill, 1964, pp. $15-64$.

\section{AUTHORS PROFILE}

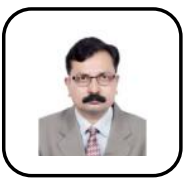

Mr.C. S. Hiwarkar currently working as Assistant Professor in Electrical Engineering Department at KDK College of Engineering, Nagpur, INDIA. He received his B.E. \& M.Tech degree from Electrical Engineering, R.T. M. Nagpur University, INDIA in 1996 \& 2007 correspondingly. He is perusing his Ph.D. in Electrical Engineering from R.T. M. Nagpur University, INDIA. His research interest is in Power system, FACTS, EHVAC-HVDC transmission system. He has 22 Years teaching experience.

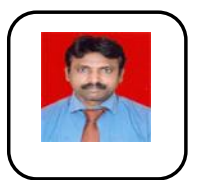

Dr. Prakash G. Burade presently working as professor,head of Electrical Department \& Dean Academics at SITRC,Nashik, India. He achieved Doctorate, PG from Govt. College of engineering, Amravati University \& Ph.D. From RTMNU, Nagpur in year 2007\& 2012 correspondingly. $\mathrm{He}$ has published 35 research papers in reputed international journal \& more than 15 papers in international conference. He has vast 23 years' experience in teaching \& research. He has travelled to foreign lands as a sitting chair \& expert talk at conferences \& seminar. He has issue 4 patents in his recognition. His field of interest is Custom power device, Power Electronics, Power system Optimization \& FACTS devices 